\title{
KALIMAT IMPERATIF DALAM ACARA “JEJAK SI GUNDUL” DI TRANS 7
}

\author{
Yoga Adi Kuncara ${ }^{1}$, \\ Universitas Ahmad Dahlan ${ }^{1}$ \\ Yogakuncara10@gmail.com ${ }^{1}$ \\ Sudarmini ${ }^{2}$ \\ Universitas Ahmad Dahlan ${ }^{2}$ \\ sudarmini@pbsi.uad.ac.id ${ }^{2}$
}

\begin{abstract}
ABSTRAK
Kalimat imperatif banyak ditemukan dalam acara "Jejak Si Gundul" di Trans 7. Peneliti memilih kalimat imperatif dalam acara "Jejak Si Gundul" untuk diteliti karena ditemukan bermacam variasi data sehingga menarik untuk diteliti lebih lanjut. Penelitian ini bertujuan untuk (1) Mendeskripsikan wujud kalimat imperatif berdasarkan kelengkapan unsur dalam acara "Jejak Si Gundul" di Trans 7, (2) Mendeskripsikan wujud kalimat imperatif berdasarkan penanda dalam acara "Jejak Si Gundul" di Trans 7. Jenis penelitian ini adalah penelitian deskriptif kualitatif. Subjek penelitian ini adalah acara "Jejak Si Gundul" di Trans 7, sedangkan objek penelitian ini adalah kalimat imperatif dalam acara "Jejak Si Gundul" di Trans 7. Metode pengumpulan data yaitu dengan menggunakan metode simak dengan teknik lanjutan simak bebas libat cakap dan teknik catat. Metode analisis data yang digunakan yaitu metode agih dengan teknik lesap dan teknik balik. Hasil penelitian yang didapatkan adalah (1) Wujud kalimat imperatif berdasarkan kelengkapan unsur ditemukan sebanyak 84 data yang terbagi atas kalimat imperatif taktransitif yang hanya terdiri dari predikat verba dasar, adjektival, frasa preposisional, kalimat imperatif lengkap transitif predikat verbal, dan kalimat imperatif lengkap taktransitif berpredikat verbal, (2) Wujud kalimat imperatif berdasarkan penanda ditemukan sebanyak 101 data yang terbagi atas 5 macam yaitu imperatif halus, imperatif ajakan dan harapan, imperatif larangan, imperatif peringatan, dan imperatif pembiaran.
\end{abstract}

Kata kunci: Kalimat Imperatif, Wujud Kalimat Imperatif, Teks Prosedur.

\section{A. PENDAHULUAN}

Bahasa merupakan suatu alat komunikasi yang digunakan manusia dan memiliki peran penting bagi masyarakat untuk melakukan interaksi di kehidupan sehari-hari. Jika tidak ada bahasa maka manusia akan kesulitan untuk berkomunikasi, berinteraksi, dan saling bertukar pendapat. Manusia merupakan makhluk sosial yang bisa mengerti dan menangkap informasi dengan baik dibandingkan dengan makhluk lainnya. Untuk bisa menangkap informasi yang disampaikan maka diperlukan sebuah komunikasi yang baik. Komunikasi yang baik ialah ketika sebuah pesan yang hendak disampaikan oleh pembicara bisa diterima dan dipahami dengan baik oleh lawan bicara. Dalam sebuah komunikasi yang sering digunakan oleh masyarakat tentu di dalamnya terdapat sebuah kalimat. Kalimat ialah suatu satuan sintaksis yang tersusun atas konstituen dasar berupa klausa serta konjungsi, lalu disertai oleh intonasi akhir (Chaer, 2015). Sedangkan menurut Kridalaksana (2011) dalam buku Kamus Linguistik 


\section{Lingua Rima: Jurnal Pendidikan Bahasa dan Sastra Indonesia \\ Vol. 11 No. 1 Januari 2022 \\ http://jurnal.umt.ac.id/index.php/lgrm}

mendefinisikan kalimat sebagai satuan bahasa yang bisa berdiri sendiri yang memiliki intonasi final serta secara aktual ataupun potensial yang terdiri dari klausa.

Berdasarkan kategori sintaksisnya, kalimat bisa dibagi menjadi empat diantaranya, kalimat deklaratif, interogatif, ekslamatif, dan kalimat imperatif. Menurut Moeliono, dkk (2017) Kalimat imperatif merupakan kalimat yang isinya memiliki fungsi untuk memerintah, menyuruh atau meminta seseorang agar dapat melakukan suatu perbuatan. Kalimat imperatif biasanya dikenal dengan kalimat perintah. Sejalan dengan pendapat tersebut, Fahmi, dkk (2018) juga mengatakan bahwa kalimat imperatif digunakan oleh seseorang untuk memberi arahan serta perintah kepada seseorang.

Peneliti tertarik untuk melakukan penelitian tentang kalimat imperatif atau kalimat perintah karena sering kita jumpai di kehidupan sehari-hari yang ada di sekita kita, baik di media cetak maupun di media televisi. Dalam media cetak biasanya kalimat imperatif dapat dijumpai di koran, majalah, bahkan di buku resep makanan. Dalam media televisi kalimat imperatif juga sering kita jumpai. Salah satunya yaitu di stasiun Trans 7. Dalam stasiun Trans 7 banyak terdapat acara edukasi yang memberikan pengetahuan dan wawasan sehingga penonton selain terhibur juga mendapatkan wawasan serta pengetahuan. Salah satu acara edukasi yang ada di Trans 7 yaitu acara "Jejak Si Gundul”.

Dipilihnya acara "Jejak Si Gundul” yaitu dalam acara tersebut terdapat langkah-langkah atau cara untuk melakukan dan membuat sesuatu yang menggunakan kalimat imperatif. Acara "Jejak Si Gundul” juga memberikan edukasi kepada penonton yang dikemas dalam bentuk hiburan sehingga penonton selain terhibur juga dapat menambah pengetahuan. Selain itu acara "Jejak Si Gundul" banyak menggunakan kalimat imperatif serta banyak disukai dan ditonton oleh anak-anak. Dipilihnya acara "Jejak Si Gundul” di Trans 7 karena acara "Jejak Si Gundul” yang ada di stasiun televisi Trans 7 memberikan edukasi kepada penonton yang dikemas dalam bentuk hiburan sehingga penonton selain terhibur juga dapat menambah pengetahuan.

Kalimat imperatif biasanya dikenal juga sebagai kalimat perintah. Kalimat imperatif adalah sebuah kalimat dimana isinya mengandung suatu reaksi kepada lawan bicara yaitu pendengar atau pembaca untuk melakukan tindakan (Chaer, 2015). Sedangkan menurut Kridalaksana (2011) kalimat imperatif adalah kalimat yang secara umum memuat maksud berupa perintah dan larangan yang mengandung intonasi perintah. Dalam bahasa indonesia 


\section{Lingua Rima: Jurnal Pendidikan Bahasa dan Sastra Indonesia \\ Vol. 11 No. 1 Januari 2022 \\ http://jurnal.umt.ac.id/index.php/lgrm}

suatu kalimat imperatif ditandai oleh partikel seru -lah atau ditandai dengan kata seperti hendaknya, jangan. Menurut pendapat Moeliono, dkk (2017) menyatakan kalimat imperatif adalah suatu kalimat yang isinya memiliki maksud untuk memerintah, menyuruh atau meminta seseorang untuk melakukan suatu tindakan. Menurut Moeliono, dkk (2017) dalam buku Tata Bahasa Baku Bahasa Indonesia Wujud kalimat imperatif dibagi menjadi 2 yaitu berdasarkan kelengkapan unsur dan berdasarkan penanda. Wujud kalimat imperatif berdasarkan kelengkapan unsur yaitu (1) kalimat imperatif taktransitif yang hanya terdiri atas predikat verba dasar, frasa preposisional, dan adjektival, (2) kalimat imperatif lengkap baik transitif maupun taktransitif yang berpredikat verbal. Sementara wujud kalimat imperatif berdasarkan penanda yaitu (1) kalimat imperatif halus, (2) kalimat imperatif ajakan dan harapan, (3) kalimat imperatif permintaan, (4) kalimat imperatif larangan, (5) kalimat imperatif peringatan, (6) kalimat imperatif pembiaran.

Penelitian tentang kalimat imperatif sudah pernah pernah dilakukan oleh orang lain. Salah satunya penelitian yang dilakukan oleh (Lindawati, 2015) yang berjudul "Kalimat Imperatif Bahasa Kepulauan Tukang Besi”. Pada penelitian tersebut didapatkan hasil yakni 7 jenis kalimat imperatif BKTB yaitu kalimat imperatif (1) taktransitif, (2) transitif, (3) halus, (4) permintaan, (5) larangan, (6) ajakan dan harapan, serta (7) pembiaran. Oleh karena itu, tujuan dalam penelitian ini yaitu (1) Mendeskripsikan wujud kalimat imperatif berdasarkan kelengkapan unsur dalam acara "Jejak Si Gundul" di Trans 7 dan (2) Mendeskripskan wujud kalimat imperatif berdasarkan penanda dalam acara “Jejak Si Gundul” di Trans 7.

\section{B. METODELOGI PENELITIAN}

Jenis penelitian ini menggunakan penelitian deskriptif kualitatif. Menurut Arikunto (2016) memberikan batasan mengenai subjek penelitian adalah sebagai benda ataupun orang dalam data penelitian yang menjadi permasalahan. Subjek penelitian ini adalah acara "Jejak Si Gundul" di Trans 7. Objek penelitian ini adalah kalimat imperatif dalam acara "Jejak Si Gundul" di Trans 7. Metode pengumpulan data yang digunakan yaitu dengan menggunakan metode simak dengan teknik lanjutan simak bebas libat cakap dan Teknik catat. Penelitian ini menggunakan alat bantu berupa kartu data dan tabulasi data.

Metode analisis data yang digunakan yaitu metode agih dengan teknik lesap untuk menganalisis wujud kalimat imperatif berdasarkan kelengkapan unsur, sementara metode agih dengan teknik balik digunakan untuk menganalisis wujud kalimat imperatif berdasarkan 
penanda. Sudaryanto (2015) menyatakan teknik lesap berfungsi untuk mengetahui kadar keintian unsur yang dilesapkan. Apabila hasil dari pelesapan tersebut tidak gramatikal, maka unsur yang bersangkutan memiliki kadar keintian yang tinggi atau bersifat inti. Sementara teknik balik teknik balik ini digunakan untuk mengetahui kadar ketegaran letak suatu unsur di dalam susunan berurutan.

\section{HASIL DAN PEMBAHASAN}

Penelitian mengenai kalimat imperatif dalam acara "Jejak Si Gundul" di Trans 7 ini dibagi menjadi dua pokok bahasan. Adapun dua pokok bahasan tersebut yaitu (1) wujud kalimat imperatif berdasarkan kelengkapan unsur dalam acara "Jejak Si Gundul" di Trans 7 (2) wujud kalimat imperatif berdasarkan penanda dalam acara "Jejak Si Gundul” di Trans 7.

\section{Wujud Kalimat Imperatif Berdasarkan Kelengkapan Unsur dalam Acara "Jejak Si Gundul" di Trans 7}

Wujud kalimat imperatif berdasarkan kelengkapan unsur dibagi menjadi dua yaitu: (1) kalimat imperatif taktransitif yang hanya terdiri dari predikat verba dasar, adjektival, frasa preposisional, dan (2) kalimat imperatif lengkap predikat verbal, baik transitif maupun taktransitif. Pada Kalimat imperatif takransitif predikat verba dasar ditemukan sebanyak 35 data, kalimat imperatif taktransitif predikat adjektival sebanyak 13 data, kalimat imperatif taktransitif predikat frasa preposisional sebanyak 3 data. Selanjutnya, untuk kalimat imperatif lengkap taktransitif predikat verbal ditemukan sebanyak 9 data, sedangkan kalimat imperatif lengkap transitif predikat verbal ditemukan sebanyak 25 data.

Kalimat imperatif taktransitif banyak ditemukan dalam acara "Jejak Si Gundul” di Trans 7. Hal tersebut dikarenakan acara tersebut merupakan acara yang disampaikan dengan menggunakan bahasa lisan yang santai, bukan acara yang menggunakan bahasa formal. Sehingga data kalimat imperatif taktransitif banyak ditemukan. Berbeda dengan kalimat imperatif transitif yang menggunakan pola S-P-O yang biasanya ditemukan dalam bahasa yang formal.

\section{a. Kalimat Imperatif Taktransitif Predikat Verba Dasar}

Berdasarkan hasil penelitian, ditemukan sebanyak 35 data kalimat imperatif taktransitif predikat verba dasar. Kalimat imperatif ini ditandai oleh predikat yang menggunakan verba dasar. Berikut contoh data yang ditemukan. 


\section{Lingua Rima: Jurnal Pendidikan Bahasa dan Sastra Indonesia \\ Vol. 11 No. 1 Januari 2022 \\ http://jurnal.umt.ac.id/index.php/lgrm}

\section{(1) Bantu saja!}

(2) Taruh sini!

Wujud kalimat imperatif pada data (1) dan (2) merupakan kalimat imperatif taktransitif predikat verba dasar. Kalimat imperatif ini hanya terdiri atas predikat yang berupa verba dasar. Penerapan teknik lesap dalam data (1) dan (2) dilakukan dengan melesapkan penanda bantu dan taruh. Jika hasil pelesapan tersebut tidak gramatikal, maka unsur tersebut memiliki kadar keintian yang tinggi atau bersifat inti.

\section{(1a) Saja! \\ (2a) Sini!}

Data (1a), dan (2a) merupakan contoh data yang telah diterapkan teknik lesap. Setelah dilakukan teknik lesap dapat diketahui bahwa kalimat tersebut menjadi tidak gramatikal. Maka didapatkan hasil bahwa unsur bantu, turun, dan taruh memiliki kadar keintian yang tinggi atau unsur tersebut bersifat inti yang tidak dapat dilesapkan.

\section{b. Kalimat Imperatif Taktransitif Predikat Adjektival}

Berdasarkan hasil penelitian, ditemukan sebanyak 13 data kalimat imperatif taktransitif predikat adjektival. Kalimat imperatif ini ditandai oleh predikat yang menggunakan bentuk adjektival atau kata sifat. Berikut contoh data yang ditemukan.

(3) Sabar dulu!

(4) Pelan saja!

Data di atas merupakan wujud kalimat imperatif taktransitif predikat adjektival. Kalimat imperatif ini hanya terdiri atas predikat yang berupa adjektival. Predikat yang berupa adjekval ialah penanda dalam kalimat imperatif ini. Untuk penanda pada data (4) yaitu kata sabar. Kalimat tersebut diucapkan oleh Gundul untuk memerintah seseorang untuk sabar terlebih dahulu untuk mengetahui cara mengolah kulit duku.

\section{c. Kalimat Imperatif Taktransitif Predikat Frasa Preposisional}

Berdasarkan hasil penelitian, ditemukan sebanyak 13 data kalimat imperatif taktransitif predikat frasa predopisional. Kalimat imperatif ini ditandai oleh predikat yang menggunakan bentuk frasa preposisional. Berikut contoh data yang ditemukan.

(5) Ke atas saja!

(6) Di sini saja! 
Wujud kalimat imperatif pada data (5) dan (6) merupakan kalimat imperatif taktransitif predikat frasa preposisional. Kalimat imperatif ini hanya terdiri atas predikat yang berupa frasa preposisional. Data (5) dan (6) merupakan wujud imperatif taktransitif predikat frasa preposisional. Setelah dilakukan teknik lesap dapat diketahui bahwa kalimat tersebut menjadi tidak gramatikal. Maka didapatkan hasil bahwa unsur ke atas, dan di sini memiliki kadar keintian yang tinggi atau unsur tersebut bersifat inti yang tidak bisa dilesapkan.

\section{d. Kalimat Imperatif Lengkap Taktransitif Predikat verbal}

Berdasarkan hasil penelitian, ditemukan sebanyak 9 data kalimat imperatif lengkap taktransitif predikat verbal. Kalimat imperatif ini ditandai oleh predikat verbal yang tidak diikuti unsur objek. Berikut contoh data yang ditemukan.

(7) Bang tangkap!

(8) Cing turun!

Wujud kalimat imperatif pada data (7) dan (8) termasuk kalimat imperatif lengkap taktransitif. Kalimat tersebut dikatakan sebagai kalimat imperatif lengkap taktransitif karena setelah predikat verbal tidak diikuti oleh unsur objek. Predikat verbal yang kalimatnya tidak diikuti oleh unsur objek merupakan penanda kalimat kalimat imperatif lengkap taktransitif predikat verbal. Pada data (7) dan (8) dapat dilihat bahwa pada kalimat tersebut setelah unsur predikat tidak diikuti oleh objek. Kalimat pada data (7) diucapkan oleh Gundul untuk memerintah seseorang untuk menangkap buah duku yang ia petik. Kalimat pada data (8) diucapkan oleh Erik untuk memerintah Cing agar turun dari pohon kelapa.

\section{e. Kalimat Imperatif Lengkap Transitif Predikat verbal}

Berdasarkan hasil penelitian, didapatkan sebanyak 25 data kalimat imperatif lengkap transitif predikat verbal. Kalimat imperatif ini ditandai oleh bentuk pasif pada predikat. Selain itu penanda lainnya yaitu predikat berupa verba transitif yakni predikat yang membutuhkan objek. Berikut contoh data yang ditemukan

(9) Semua adonan dimasukkan dalam wadah!

(10) Bumbunya ditumis dalam minyak panas ya!

Wujud kalimat imperatif pada data di atas merupakan kalimat imperatif lengkap transitif. Kalimat tersebut dikatakan kalimat imperatif lengkap transitif karena menggunakan bentuk pasif pada predikatnya. Penggunaan bentuk pasif pada predikat kalimat merupakan penanda kalimat imperatif lengkap transitif. Pada data (9) dan (10) dapat dilihat bahwa 
penggunaan bentuk pasif di pada kata dimasukkan dan ditumis adalah penanda kalimat imperatif lengkap transitif.

Setelah dilakukan teknik lesap pada data dapat diketahui bahwa kalimat tersebut menjadi tidak gramatikal. Maka didapatkan hasil bahwa unsur dimasukkan dan ditumis memiliki kadar keintian yang tinggi atau unsur tersebut bersifat inti yang tidak dapat dilesapkan.

\section{Wujud Kalimat Imperatif Berdasarkan Penanda dalam Acara “Jejak Si Gundul” di Trans 7}

Wujud kalimat imperatif berdasarkan penanda yang ditemukan sebanyak 5 macam yang meliputi: yaitu (1) Imperatif halus sebanyak 16 (2) Imperatif ajakan dan harapan sebanyak 41 data (3) Imperatif larangan sebanyak 25 data (4) Imperatif peringatan sebanyak 17 data, serta (5) Imperatif pembiaran sebanyak 2 data. Kalimat imperatif ajakan dan harapan banyak ditemukan dalam acara "Jejak Si Gundul" di Trans 7. Hal tersebut dikarenkan acara "Jejak Si Gundul” merupakan sebuah acara yang memberikan informasi atau pengetahuan kepada penonton yang di dalamnya terdapat cara membuat atau melakukan sesuatu. Hal tersebut membuat acara "Jejak Si Gundul” banyak menggunakan kalimat imperatif ajakan dan harapan.

\section{a. Kalimat Imperatif Halus}

Berdasarkan hasil penelitian, ditemukan sebanyak 13 data kalimat imperatif halus. Penanda kalimat imperatif ini ditandai oleh kata tolong, silakan, dan coba. Berikut ini contoh data yang ditemukan.

(1) Tolong bantu isi!

(2) Silakan pilih siapa!

Kalimat pada data (1) dan (2) merupakan kalimat imperatif halus dengan penanda tolong dan silakan. Kalimat imperatif halus digunakan untuk menghalus isi kalimat imperatif. Untuk melihat seberapa jauh kadar ketegaran letak kata tersebut, maka digunakan teknik balik dalam menganalisis data. Perhatikan kalimat berikut ini.

(1a) Bantu isi, tolong!

(*1b) Bantu tolong isi!

(*1c) Isi tolong bantu!

(*1d) Isi bantu tolong! 
Berdasarkan hasil penerapan teknik balik pada data (1a) dimana letak penanda yaitu kata tolong diletakkan di akhir kalimat, kemudian tidak mengubah urutan unsur setelah penanda serta diberi tanda koma sebelum kata tolong, maka didapatkan bahwa kata tolong pada kalimat di atas memiliki kadar ketegaran yang rendah. Sedangkan kalimat pada data (1b), (1c), dan (1d) dapat dikatakan bahwa kata tolong sebagai kalimat imperatif pada kalimat di atas memiliki kadar ketegaran letak yang tinggi. Hal tersebut terlihat dari hasil penerapan teknik balik pada data dimana susunan kalimatnya menjadi tidak gramatikal, sehingga mengakibatkan makna atau informasi yang ingin disampaikan menjadi tidak tersampaikan secara baik. Begitu juga dengan data (2) dimana letak penanda yaitu kata silakan jika diletakkan di akhir kalimat, lalu tidak mengubah susunan unsur setelah penanda serta diberi tanda koma sebelum penanda, maka dapat diketahui bahwa kata silakan memiliki kadar ketegaran yang rendah.

\section{b. Kalimat Imperatif Ajakan da Harapan}

Berdasarkan hasil penelitian, ditemukan sebanyak 41 data kalimat imperatif ajakan dan harapan. Penanda kalimat imperatif ajakan dan harapan ditandai kata ayo, ayolah dan mari. Berikut ini contoh data yang ditemukan.

(3) Ayo bungkus saja sekarang!

(4) Ayolah langsung meluncur ke TKP!

Kalimat di atas merupakan kalimat imperatif ajakan dan harapan dengan penanda ayo, ayolah, dan mari. Kalimat imperatif ajakan dan harapan digunakan untuk mengajak atau berharap seseorang agar melakukan sesuatu tindakan atau perbuatan.

(3a) Bungkus saja sekarang, ayo!

(*3b) Bungkus saja ayo sekarang!

(*3c) Sekarang ayo bungkus saja!

(*3d) Sekarang bungkus saja ayo!

Berdasarkan hasil penerapan teknik balik pada data (3a) dimana letak penanda yaitu kata ayo diletakkan di akhir kalimat, kemudian tidak mengubah urutan unsur setelah penanda serta diberi tanda koma sebelum kata ayo, maka didapatkan bahwa kata ayo pada kalimat di atas memiliki kadar ketegaran yang rendah. Sedangkan kalimat pada data (3b), (3c), dan (3d) dapat dikatakan bahwa kata ayo sebagai kalimat imperatif pada kalimat di atas memiliki kadar ketegaran letak yang tinggi. Data (4) juga sama halnya dengan data (3). 


\section{c. Kalimat Imperatif Larangan}

Berdasarkan hasil penelitian, ditemukan sebanyak 25 data kalimat imperatif larangan. Untuk penanda kalimat imperatif larangan ditandai oleh kata jangan. Berikut ini contoh data yang ditemukan.

(5) Jangan langsung dimakan!

(6) Jangan jauh-jauh!

Kalimat di atas merupakan kalimat imperatif larangan dimana penandanya yaitu kata jangan. Kalimat imperatif larangan digunakan ketika menyuruh lawan bicara untuk tidak melakukan sesuatu. Kalimat pada data (5) ditandai oleh kata jangan yang diucapkan oleh Gundul untuk melarang seseorang agar tidak langsung makan olahan daging kambing. Pada data (6) kalimat tersebut ditandai oleh kata jangan yang diucapkan oleh Septa yang melarang anak-anak supaya main tidak jauh- jauh dari rumah.

\section{d. Kalimat Imperatif Peringatan}

Berdasarkan hasil penelitian, ditemukan sebanyak 17 data kalimat imperatif larangan. Penanda kalimat imperatif peringatan ditandai oleh kata hati-hati dan awas. Berikut ini contoh data yang ditemukan.

(7) Hati-hati saat mencelupkan bola-bola udang!

(8) Awas dahan jatuh!

Kalimat di atas adalah kalimat imperatif peringatan dengan penanda kata hati-hati. Kalimat imperatif peringatan digunakan untuk mengingatkan orang lain supaya tidak melakukan sesuatu yang berbahaya atau bisa berakibal fatal. Data (7) dan (8) termasuk kalimat imperatif peringatan yang ditandai oleh kata hati-hati dan awas. Letak kata hati-hati dan awas pada data tersebut memiliki kadar ketegaran letak yang tinggi. Hal itu terlihat dari hasil penggunaan teknik balik yang dikenakan pada data. Susunan kalimat pada data menjadi tidak gramatikal yang mengakibatkan makna atau informasi yang terdapat di dalamnya menjadi berubah.

\section{e. Kalimat Imperatif Pembiaran}

Berdasarkan hasil penelitian, ditemukan sebanyak 2 data kalimat imperatif pembiaran. Penanda kalimat imperatif peringatan ditandai oleh kata biar. Berikut ini contoh data yang ditemukan.

(9) Biar aku saja yang manjat! 


\section{Lingua Rima: Jurnal Pendidikan Bahasa dan Sastra Indonesia \\ Vol. 11 No. 1 Januari 2022 \\ http://jurnal.umt.ac.id/index.php/lgrm}

(10) Biar dia tahu ada rasa alpukatnya!

Kalimat dalam data (9) dan (10) merupakan kalimat imperatif pembiaran dengan penanda yaitu kata biar. Kalimat imperatif pembiaran digunakan untuk meminta seseorang membiarkan sesuatu terjadi atau berlangsung.

Data di atas merupakan imperatif peringatan yang ditandai oleh kata biar. Letak kata biar pada data tersebut memiliki kadar kegetaran yang tinggi. Hal tersebut akan terlihat setelah data dikenakan teknik balik, susunan kalimatnya menjadi tidak gramatikal sehingga makna atau informasi yang terkandung di dalamnya menjadi berubah.

\section{SIMPULAN DAN SARAN}

Berdasarkan penelitian yang telah dijabarkan, maka dapat disimpulkan sebagai berikut. Wujud kalimat imperatif berdasarkan kelengkapan unsur dibagi menjadi dua yaitu: (1) kalimat imperatif taktransitif yang hanya terdiri dari predikat verba dasar, adjektival, frasa preposisional, dan (2) kalimat imperatif lengkap predikat verbal, baik transitif maupun taktransitif. Pada Kalimat imperatif takransitif predikat verba dasar ditemukan sebanyak 35 data, kalimat imperatif taktransitif predikat adjektival sebanyak 13 data, kalimat imperatif taktransitif predikat frasa preposisional sebanyak 3 data. Selanjutnya, untuk kalimat imperatif lengkap taktransitif predikat verbal ditemukan sebanyak 9 data, sedangkan kalimat imperatif lengkap transitif predikat verbal ditemukan sebanyak 25 data. Kalimat imperatif taktransitif banyak ditemukan dalam acara "Jejak Si Gundul" di Trans 7. Hal tersebut dikarenakan acara tersebut merupakan acara yang disampaikan dengan menggunakan bahasa lisan yang santai, bukan acara yang menggunakan bahasa formal. Sehingga data kalimat imperatif taktransitif banyak ditemukan. Wujud kalimat imperatif berdasarkan penanda yang ditemukan sebanyak 5 macam yang meliputi: yaitu (1) Imperatif halus sebanyak 16 (2) Imperatif ajakan dan harapan sebanyak 41 data (3) Imperatif larangan sebanyak 25 data (4) Imperatif peringatan sebanyak 17 data, serta (5) Imperatif pembiaran sebanyak 2 data. Kalimat imperatif ajakan dan harapan banyak ditemukan dalam acara "Jejak Si Gundul" di Trans 7. Hal tersebut dikarenkan acara "Jejak Si Gundul” merupakan sebuah acara yang memberikan informasi atau pengetahuan kepada penonton yang di dalamnya terdapat cara membuat atau melakukan sesuatu. Adapun saran untuk penelitian berikutnya yaitu hasil penelitian ini bisa dijadikan referensi bagi peneliti selanjutnya yang akan melakukan penelitian mengenai kalimat imperatif atau kalimat perintah. 


\section{E. DAFTAR PUSATAKA}

Arikunto, S. (2016). Prosedur Penelitian : Suatu Pendekatan Praktik. Jakarta: Rineka Cipta.

Astutik, D. (2015). Deskripsi Kalimat Imperatif dalam Bahasa Lisan Ustadz Maulana dengan Tema "Bersedekah pada Orang Tua" dan "Di Balik Sebuah Musibah" di Youtube". Universitas Muhammadiyah Surakarta.

Chaer, A. (2015). Sintaksis Bahasa Indonesia. Jakarta: Rineka Cipta.

Darmawanti, A. A. S., Indriani, M. S., Astika, M. (2019). Analisis Kalimat Imperatif Dalam Video Tutorial Skincare Clarin Hayes Di Youtube Dan Relevansinya Pada Pembelajaran Teks Prosedur Di Sma. Jurnal Pendidikan Bahasa Dan Sastra Indonesia Undiksha, 9(2), 324-333. https://doi.org/10.23887/jjpbs.v9i2.20488

Fahmi, N., Mahmud, S., \& Azwardi. (2018). Analisis Kalimat Imperatif yang Digunakan Guru dalam Pembelajaran Bahasa Indonesia di SMA Inshafuddin Banda Aceh. 3(1), 219-230.

Kridalaksana, H. (2011). Kamus Linguistik. Jakarta: Gramedia Pustaka Utama.

Lindawati. (2015). Kalimat Imperatif Bahasa Kepulauan Tukang Besi. Humanika, 3(15), 1017.

Moeliono, A. M., Lapoliwa, H., Alwi, H., Sasangka, S. S., \& Sugiyno. (2017). Tata Bahasa Baku Bahasa Indonesia. Jakarta: Badan Pengembangan dan Pembinaan Bahasa.

Moleong, L. J. (2018). Metodologi Penelitian Kualitatif. Bandung: PT Remaja Rosdakarya.

Nuryadin, T. R., \& Wagiati. (2020). Kalimat Imperatif dalam Iklan Layanan Masyarakat Berbahasa Arab Terkait Covid-19 di SBS Australia. Diglosia: Jurnal Kajian Bahasa, Sastra, Dan Pengajarannya, 3(4), 385-392.

Sudaryanto. (2015). Metode dan Aneka Teknik Analisis Bahasa: Pengantar Penelitian Wahana Kebudayaan secara Linguistis. Yogyakarta: Sanata Dharma University Press.

Sugiyono. (2019). Metode Penelitin Kuantitatif,Kualitatif, dan R\&D. Yogyakarta: ALFABETA.

Suryatin, E. (2019). Jenis, Bentuk, Dan Makna Kalimat Perintah Dalam Kisdap "Satipis Apam Barabai" Karya Ida Komalasari. UNDAS: Jurnal Hasil Penelitian Bahasa Dan Sastra, 15(2), 199. https://doi.org/10.26499/und.v15i2.1784 